\title{
AN AERIAL MULTISPECTRAL THERMOGRAPHIC SURVEY OF THE OAK RIDGE RESERVATION FOR SELECTED AREAS K-25, X-10, AND Y-12
}

OAK RIDGE, TENNESSEE

DBTARBUTION OF THS DOCUMENT 8 UminteD

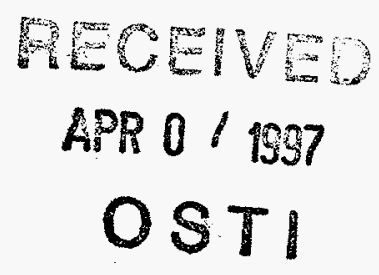

MASTER 


\section{DISCLAIMER}

This report was prepared as an account of work sponsored by an agency of the United States government. Neither the United States government nor an agency thereof, or any of their employees, makes a warranty, express or implied, or assumes legal liability or responsibility for the accuracy, completeness, or usefulness of any disclosed information, apparatus, product, or process or represents that its use would not infringe privately owned rights. Reference herein to a specific commercial product, process, or service by trade name, trademark, manufacturer, or otherwise does not necessarily constitute or imply an endorsement, recommendation, or favoring by the United States government or an agency thereof. The views and opinions of the authors expressed herein do not necessarily state or reflect those of the United States government or an agency thereof.

This report has been reproduced directly from the best available copy.

This report is available to DOE and DOE contractors from the Office of Scientific and Technical Information, P.O. Box 62, Oak Ridge, TN 37831. Call (615) 576-8401 to obtain prices.

This report is available to the public from the National Technical Information Service, U.S. Department of Commerce, 5285 Port Royal, Springfield, VA 22161. 


\section{DISCLAMMER}

Portions of this document may be illegible in electronic image products. Images are produced from the best available original document. 


\title{
AN AERIAL MULTISPECTRAL THERMOGRAPHIC SURVEY OF THE OAK RIDGE RESERVATION FOR SELECTED AREAS K-25, X-10, AND Y-12
}

\author{
OAK RIDGE, TENNESSEE
}

DATE OF SURVEY: JUNE 6, 1996

I. W. Ginsberg

Project Scientist

This Document is UNCLASSIFIED

T. M. Hayes

Authorized Derivative Classifier

This work was performed for the U.S. Department of Energy by EG\&G/EM under Contract Number DE-AC08-93NV11265 and Bechtel Nevada under Contract Number DE-AC08-96NV11718. 


\section{ABSTRACT}

During June 5-7, 1996, the Department of Energy's Remote Sensing Laboratory performed day and night multispectral surveys of three areas at the Oak Ridge Reservation: $\mathrm{K}-25, \mathrm{X}-10$, and $\mathrm{Y}-12$. Aerial imagery was collected with both a Daedalus DS1268 multispectral scanner and National Aeronautics and Space Adminstration's Thermal Infrared Multispectral System, which has six bands in the thermal infrared region of the spectrum. Imagery from the Thermal Infrared Multispectral System was processed to yield images of absolute terrain temperature and of the terrain's emissivities in the six spectral bands. The thermal infrared channels of the Daedalus DS1268 were radiometrically calibrated and converted to apparent temperature. A recently developed system for geometrically correcting and geographically registering scanner imagery was used with the Daedalus DS1268 multispectral scanner. The corrected and registered 12-channel imagery was orthorectified using a digital elevation model. 


\section{ACKNOWLEDGEMENTS}

The field crew members, to include T. McCreary, V. Young, M. Rivera, and D. Howard, are acknowledged for their efforts in collecting data. R. Demas and S. Brewster are acknowledged as the analysts and E. Lewis-King for the orthorectification effort. Also, the personnel from the Oak Ridge National Laboratory, especially Amy King, are acknowledged for their aid and support. 


\section{CONTENTS}

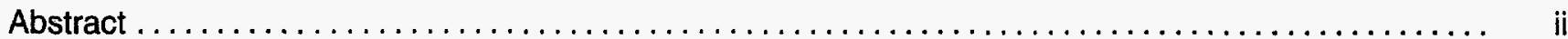

Acknowiedgements $\ldots \ldots \ldots \ldots \ldots \ldots \ldots \ldots \ldots \ldots \ldots \ldots \ldots \ldots \ldots \ldots \ldots \ldots \ldots \ldots$

\section{Sections}

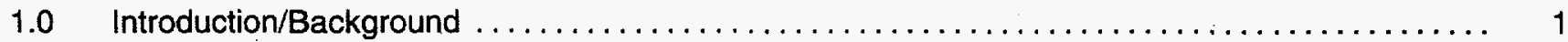

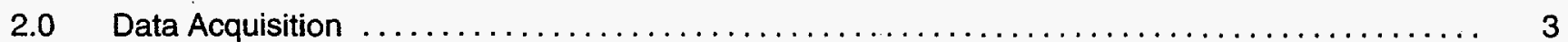

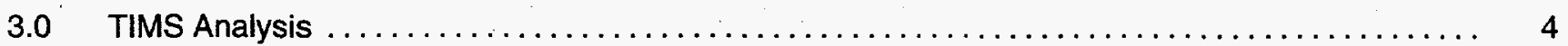

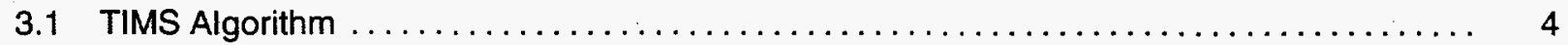

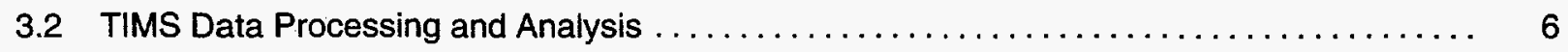

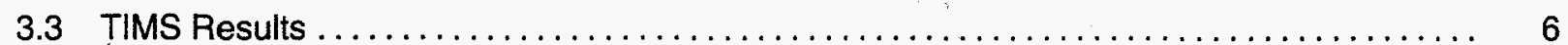

4.0 Daedalus DS1268 Image Processing and Deliverables $\ldots \ldots \ldots \ldots \ldots \ldots \ldots \ldots \ldots \ldots \ldots$

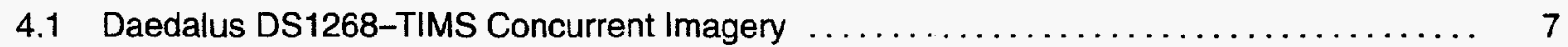

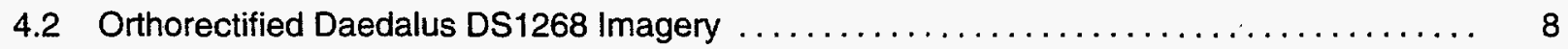

Figures

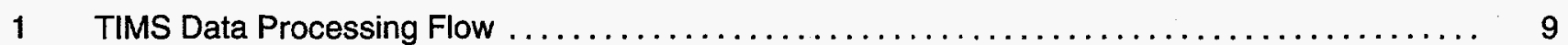

2 Example of Estimated Absolute Temperture Image $\ldots \ldots \ldots \ldots \ldots \ldots \ldots \ldots \ldots \ldots \ldots \ldots$

3 Example of Estimated Emissivity Image for TIMS Channel $3 \ldots \ldots \ldots \ldots \ldots \ldots \ldots \ldots \ldots \ldots$

4 Geocoded, Orthorectified, and Mosaicked Multispectral

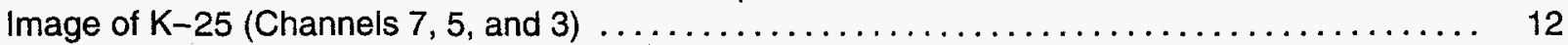

B-1 Directory and File Structure for Processed TIMS Data $\ldots \ldots \ldots \ldots \ldots \ldots \ldots \ldots \ldots \ldots \ldots$

\section{Tables}

1 Thermal Infrared Multispectral System Specifications $\ldots \ldots \ldots \ldots \ldots \ldots \ldots \ldots \ldots \ldots \ldots \ldots$

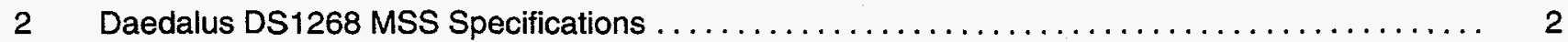

3 Measured Bandwidths at 50 Percent Responsivity $\ldots \ldots \ldots \ldots \ldots \ldots \ldots \ldots \ldots \ldots \ldots \ldots$

A-1 Data Derived from JPL Measurements ................................. 20

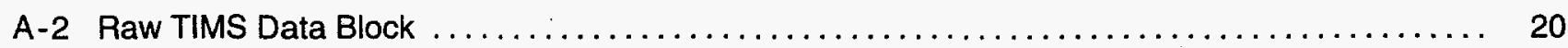

\section{Appendix}

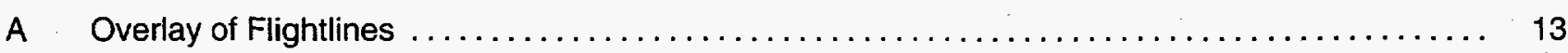

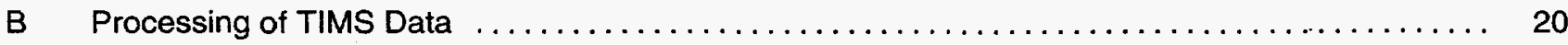

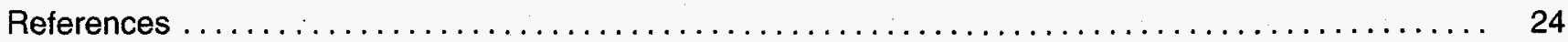




\subsection{INTRODUCTION/BACKGROUND}

The Department of Energy (DOE), Oak Ridge Operations Office, Environmental Restoration Division, requested an aerial thermographic (infrared) survey of selected areas of the Oak Ridge Reservation. The following areas were surveyed:

(a) A 3-by 3-mile area covering K-25 including the junction of Poplar Creek and the Clinch River.

(b) A3-by 3-mile area covering X-10 including the junction of White Oak Creek and the Clinch River.

(c) An area of waste sites and the industrial buildings in Bear Creek Valley at $\mathrm{Y}-12$.

In addition to the thermal infrared (TIR) collections, the request included delivery of orthographic multispectral imagery of a 1 - by 1 -mile area centered at $\mathrm{K}-25$.

The DOE Remote Sensing Laboratory (RSL) in Las Vegas, Nevada, responded to this request using an airborne multispectral thermal infrared scanner and a multispectral scanner (MSS) and a variety of ground-based sensors from the RSL inventory. The airborne sensors for the mission included the National Aeronautics and Space Administration (NASA) Thermal Infrared Multispectral System (TIMS) and the Daedalus DS1268 MSS, which collected imagery concurrently. The ground-based sensors included a weather station, a radiosonde system, and hand-held temperature radiometers.

The TIMS scanner is a multi-band infrared scanner that collects imagery in six thermal bands between about 8 and 12 microns. A summary of the TIMS performance parameters is presented in Table 1, and a description of the spectral bands is provided in Appendix A. RSL operated the TIMS sensor through a Memorandum of Understanding between NASA Headquarters and the DOE Nevada Operations Office.

The Daedalus DS1268 MSS, manufactured by Daedalus Enterprises, is owned by DOE. Performance parameters are presented in Table 2, and a description of the spectral bandwidths is presented in Table 3. Note that the Daedalus DS1268 collects broad-band thermal imagery in the 8.5-12 micron region of the spectrum, providing spectral overlap with the TIMS.

In addition to the electrooptical systems and meteorological sensors, RSL employed a system that is being developed for monitoring and recording the orientation and position of airborne sensors-the Geometric Correction System (GCS). The GCS includes an Inertial Navigation System (INS) for determining angular orientation and motion and a Geographic Positioning System (GPS) for updating INS position and time. The GCS also includes software for applying the collected data to the geometric correction of scanner imagery and to geocode that imagery. The GCS system provides the data and analytical means to produce orthorectified scanner imagery.

TIR imagery provides useful information about rooftops, soil moisture and surface hydrology, and surface disturbance. This is because the thermal properties of materials together with thermal loading determine an object's temperature. The temperature alone, however, does not determine emitted radiance; the emissivity is also a factor. Emissivity is generally a function of wavelength; therefore, there is a problem in determining both the temperature and the spectral emissivity by measuring only the spectrai radiance. Unfortunately, this problem 
remains even if radiance measurements are taken in multiple TIR bands. Each spectral measurement introduces an additional unknown: another spectral emissivity.

RSL has developed an algorithm that partially solves this problem by using a pair of approximations and a constraint on the value of estimated temperature. This method will be discussed in Section 3.1.

Table 1. Thermal Infrared Multispectral System Specifications

\begin{tabular}{l|l}
\hline & TIMS Specifications \\
\hline Number of Channels & 6 \\
Operating Wavelengths & $8.2-12.2$ \\
Scan Rate & $7.3,8.7,12$, or 25 scans/second (selectable) \\
Instantaneous Field-of-View & 2.5 milliradians \\
Total Field-of-View & 76.56 degrees \\
Noise Equivalent Temperature & 0.3 Kelvin, approximate \\
Difference (NE $\Delta$ T) & \pm 15 degrees \\
Roll Correction & Two controllable, thermal blackbodies \\
Reference Sources & 638 \\
Video Words/Scan Line & $0.5,1,2,4$, or 8 (selectable) \\
Digitizer Gains &
\end{tabular}

Table 2. Paedalus DS1268 MSS Specifications

\begin{tabular}{l|l}
\hline \multicolumn{2}{c}{ Daedalus DS1268 MSS Specifications } \\
\hline Number of Channels & 12 \\
Operating Wavelengths & 0.42 micrometers to 12.5 micrometers \\
Scan Rate & $12.5,25,50$, or 100 scans/second (selectable) \\
Instantaneous Field-of-View & 2.5 milliradians (1.25 mrad half-angle mode) \\
Total Field-of-View & 85.92 degrees \\
Temperature Resolution & 0.1 Kelvin, approximate \\
Roll Correction & \pm 15 degrees \\
Reference Sources & Infrared, two controllable, thermal blackbodies \\
Video Words/Scan Line & 716 \\
Digitizer Gains & $0.5,1,2,4$, or 8 (selectable) \\
\hline
\end{tabular}


Table 3. Measured Bandwidths at 50 Percent Responsivity

\begin{tabular}{c|c|l}
\hline $\begin{array}{c}\text { Channel } \\
\text { Number }\end{array}$ & $\begin{array}{c}\text { Wavelength } \\
(\mu \mathrm{m})\end{array}$ & $\begin{array}{c}\text { Color/Spectral } \\
\text { Region }\end{array}$ \\
\hline 1 & $0.42-0.44$ & Violet/Blue \\
\hline 2 & $0.46-0.51$ & Blue/Green \\
\hline 3 & $0.52-0.59$ & Green/Yellow \\
\hline 4 & $0.59-0.62$ & Orange \\
\hline 5 & $0.62-0.67$ & Red \\
\hline 6 & $0.67-0.72$ & Near Infrared \\
\hline 7 & $0.73-0.85$ & Near Infrared \\
\hline 8 & $0.84-0.97$ & Near Infrared \\
\hline 9 & $1.59-1.79$ & Middle Infrared \\
\hline 10 & $2.1-2.4$ & Middle Infrared \\
\hline 11 & $8.28-10.67$ & Thermal Infrared \\
\hline 12 & $8.28-10.67$ & Thermal Infrared \\
\hline \multicolumn{4}{|c|}{ Alternate Configuration } \\
\hline 10 & \multicolumn{2}{|c}{ EMPTY } \\
\hline 11 & $3.16-5.20$ & Thermal Infrared \\
\hline 12 & $8.28-10.67$ & Thermal Infrared \\
\hline
\end{tabular}

\subsection{DATA ACQUISITION}

The survey consisted of 18 flight lines. Each set of lines was flown during daylight and predawn hours. Eight flight lines were flown at 4000 feet above ground level (AGL) and 10 were flown at 2000 feet AGL. In addition, some of the designated lines at 2000 feet AGL were also flown at 4000 feet AGL to ensure complete coverage.

The daylight coverage was flown under relatively clear skies providing excellent data quality. The predawn coverage was flown in very high humidity, resulting in a smaller range of pixel values because of atmospheric water-vapor absorption and reemission. The predawn flights were also attempted on june 7 but were cancelled because of rain. 
A separate set of lines at 2000 feet AGL were flown again during the daylight hours without the MSS gyro but with the GCS system, which is currently being developed by the RSL. The data from the GCS system permits geometric correction of the imagery using specially developed software.

During each flight, a weather balloon was launched to provide temperature, relative humidity, and pressure profiles. Radiometer readings were taken at various areas to provide true temperatures. Spectrometer data were taken of the parking lot at $\mathrm{K}-25$ during daylight flights.

Included in this report is a set of images with the portion of each flightline, where imagery was collected, overlaid in green or yellow on a SPOT panchromatic image (see Appendix A). The color represents the aircraft's altitude, yellow for 2000 feet AGL and green for 4000 feet AGL. Images for both the MSS and TIMS are given because, even though the sensors collected concurrently, the locations where the scanners began and stopped collecting were not precisely the same.

\subsection{TIMS ANALYSIS}

\subsection{TIMS Algorithm}

As previously stated, a single measurement of spectral radiance is not sufficient to determine the absolute temperature of a surface because Planck's equation relating the radiance to the temperature also includes the emissivity, which usually is also unknown. If the emissivity were not a function of wavelength, simultaneous measurements of two spectral radiances would allow determination of both temperature and emissivity. Unfortunately, in most cases the emissivity is a function of wavelength; therefore, each additional spectral measurement brings in another unknown. This is apparent when the Planck equations for two wavelengths are examined:

$$
\begin{aligned}
& L_{\lambda_{1}}=\varepsilon\left(\lambda_{1}\right) \cdot c_{1} \cdot\left\{\pi \cdot \lambda_{1}^{5} \cdot\left[e^{c_{2} /\left(\lambda_{1} \cdot T\right)}-1\right]\right\}^{-1} \\
& L_{\lambda_{2}}=\varepsilon\left(\lambda_{2}\right) \cdot c_{1} \cdot\left\{\pi \cdot \lambda_{2}^{5} \cdot\left[e^{c_{2} /\left(\lambda_{2} \cdot T\right)}-1\right]\right\}^{-1}
\end{aligned}
$$

where $L_{\lambda}$ represents the spectral radiances, $\varepsilon$ represents the emissivities, $\lambda$ represents the wavelengths, and $T$ represents the absolute temperature, and $c_{1}$ and $c_{2}$ are known constants. An additional equation or constraint is needed that does not introduce new unknowns.

Previously, most efforts to provide an additional equation or constraint involved assumptions ranging from assuming a value for the emissivity at one wavelength to assuming a value for the average 
emissivity over the scene. Recently, it has been suggested that the introduction of two approximations would enable a simple constraint to be used that allows for the determination of temperature and emissivities on a pixel-by-pixel basis. The two approximations are as follows:

$$
\begin{gathered}
L_{\lambda} \approx \varepsilon(\lambda) \cdot c_{1} \cdot\left\{\pi \cdot \lambda^{5} \cdot\left[e^{c_{2} /(\lambda \cdot T)}-1\right]\right\}^{-1} \quad \text { (Wein approximation) } \\
\ln (\varepsilon-1) \approx \varepsilon-1
\end{gathered}
$$

For ease of calculation, the "apparent temperature" $T$ is introduced as defined by the following equation:

$$
L_{\lambda}=\varepsilon(\lambda) \cdot c_{1} \cdot\left\{(\pi \cdot \lambda)^{5} \cdot\left[e^{c_{2} /(\lambda \cdot T)}-1\right]\right\}^{-1}
$$

The two approximations permit a relationship to be developed between emissivities at two wavelengths:

$$
\varepsilon\left(\lambda_{1}\right)=1-\lambda_{2} / \lambda_{1}-\lambda_{2} / \lambda_{1} \cdot \varepsilon\left(\lambda_{2}\right)+c_{2} / \lambda_{1} \cdot\left(1 / T_{2}-1 / T_{1}\right)
$$

This equation allows one unknown emissivity to be eliminated from the two radiance expressions of the Wein approximation to the Planck equations. The result is two equations with only two unknowns, which are easily solved for the absolute temperature.

However, we are not quite at a solution because there are two solutions to the equation for absolute temperature. The constraint found to be most effective is to select the solution that is closer to the maximum apparent temperature, short of sensor saturation. Using the calculated absolute temperature, the emissivities may be obtained from each Planck equation using the measured spectral radiance or apparent temperature.

The complete process carried out by this algorithm yields an effective decoupling (or separation) of absolute temperature from emissivity, using a minimal condition of constraint. The algorithm is therefore called TEEMS, an acronym for "TEmperature-EMissivity. Separation."

An accuracy assessment of the TEEMS algorithm was made using randomly generated temperatures between 250 and $373 \mathrm{~K}$, together with randomly generated emissivities between 0.99 and 0.80 . The calculated temperatures are consistently lower than the actual by $2 \mathrm{~K}$ or less. Accordingly, the 
emissivities in each band are higher than the actual values, but the spectral shape of the emissivity is preserved. This preservation of spectral shape is especially useful for identifying materials on the basis of emissivity.

The method just described utilizes spectral radiances. However, the TIMS channels, though of moderate bandwidths, are neither sufficiently narrow nor well shaped to yield a satisfactory approximation to spectral radiance. RSL's approach to obtaining the needed spectral radiances was to use the "Moments" method ${ }^{1}$ to calculate a wavelength, effective bandwidth, and spectral radiance for each TIMS channel.

\subsection{TIMS Data Processing and Analysis}

To obtain absolute temperature and the six-band emissivities from the raw, recorded data, there is a set of processes to which these data are subjected. The flow of those processes is diagrammed in Figure 1 and discussed below.

In preparation for analyzing the data to obtain temperature and emissivities, the data is geometrically corrected and calibrated and atmospheric compensation applied. Geometric correction is for panoramic (S-bend) distortion and employs resampling with a polynomial approximation to the tangent function.

Calibration and atmospheric compensation are done with the TEASE software, developed and provided by the Jet Propulsion Laboratory (JPL). Two blackbodies internal to the TIMS sensor are the references for the two-point calibration of the data. The outputs of the calibration process (TIMSCAL software) are band radiances and apparent temperature at the aperture for each band. Atmospheric compensation is obtained using the TIMSCAL2 package in TEASE. The input is the band radiances output of the calibration process together with atmospheric parameters obtained either from a model or from measurements. RSL used radiosonde and ground-based measurements of the atmospheric parameters. The outputs were band radiances and apparent temperature at the target surface. The final processing step consists of converting the band radiances at the target to equivalent spectral radiances.

Finally, the TEEMS algorithm is used with the spectral radiances, wavelengths, and apparent temperatures to produce seven images for each flight line: an absolute or Celsius temperature image and the six spectral-band emissivities. A detailed description of the processing and analyzing steps and the software developed by RSL is presented in Appendix B.

\subsection{TIMS Results}

The TIMS temperature and emissivity images are provided in digital format on CD-ROM (see Appendix B). The data are floating point with temperature in Celsius rather than Kelvin to ease the 
interpretation of the data. The raw data have no saturation but do contain some clipped pixels at the low-value end. The clipping has two causes:

(a) Some structures in the scene are bare metal, which (having low emissivity) yield radiances below the sensible limit of the sensor.

(b) Roll correction in the sensor results in a proportionate loss of imagery when the roll exceeds two degrees in either direction.

The operative cause is readily apparent from an examination of the imagery-roll produces clipped pixels at the edges of the imagery, typically with a smooth concave boundary. To facilitate recognition, clipped pixels are assigned the value "-99" and are present in all seven images. An example of an absolute temperature image is shown in Figure 2, and an emissivity image of the same area is shown in Figure 3.

There is an additional caveat. The mounting of the TIMS in the Citation aircraft produces vignetting of the sensor's field-of-view, with a resultant decrease in the scene radiance at the edges of the imagery. The effect on the pixels at the edges becomes worse as the edges are approached; about 50 pixels on each edge are affected, totaling 100 of the 638 pixels comprising a scan line. This problem was known when the collection was planned; therefore, flight lines were flown with at least 30 percent sidelap. Consequently, the vignetted pixels can be deleted without losing coverage.

TIMS imagery was collected at altitudes chosen to provide pixels with dimensions less than 1.5 and 3 meters (about 2000 and 4000 feet AGL, respectively). Flying conditions were such, however, that it was not possible to obtain contiguous scan lines at a 2000 -foot altitude; there was about 30 percent underscan. It is possible, though, to interpolate using either the concurrent Daedalus DS1268 TIR channel or the TIMS imagery acquired at a 4000 -foot altitude. The Daedalus DS1268 scanner was able to obtain contiguous data at a 2000 -foot altitude because it could scan at higher speed.

\subsection{DAEDALUS DS1268 IMAGE PROCESSING AND DELIVERABLES}

Daedalus DS1268 multispectral imagery was collected as an adjunct and complementary to the TIMS imagery. It was collected on a separate survey to provide data for the creation of orthorectified imagery of a 1 - by 1 -mile area centered at the $\mathrm{K}-25$ site.

\subsection{Daedalus DS1268-TIMS Concurrent Imagery}

The requested scope of this project restricted processing Daedalus DS1268 multispectral data to the creation of a digital, mosaicked, and orthorectified image. Not withstanding the request, it was believed that a level of elementary processing of the imagery collected concurrently with TIMS imagery might be very useful to the customer. Possible uses would include (a) interpolating between 
TIMS scan lines in the low-altitude imagery and (b) multispectral analysis in conjunction with thermal analysis of buried waste sites. The radiometric processing of this imagery was restricted to calibrating the thermal channels and deriving apparent temperature, and the geometric processing was restricted to correcting all channels for panoramic distortion produced by scanning. The processed imagery was delivered on CD-ROM.

\subsection{Orthorectified Daedalus DS1268 Imagery}

As stated in Section 2.0, a set of lines were flown during the day over the $\mathrm{K}-25$ area with the Daedalus DS1268 sensor to collect data for the specific purpose of creating an orthorectified image. The data were collected without the roll-correction gyro normally used with this scanner. Instead, the INS and GPS were used to record sensor attitude and position. The GPS provided correction for the drift of the INS and also provided the master clock for correlating all time-dependent data. The INS and GPS were combined and interfaced to function as a single "geocoding system"- the GCS.

Creation of geocoded, orthorectified, and mosaicked imagery requires information about the angular orientation and position of the scanner for each pixel. The information is obtainable from the GCS, which also provides a master clock for time-stamping each pixel permitting sensor orientation and position to be matched with that pixel. In addition to sensor orientation and position, orthorectification requires information about terrain elevation so that pixel displacements produced by elevation can be removed. That information was obtained from the digital elevation model (DEM) supplied by the Oak Ridge National Laboratory (ORNL). A false color simulation of the area, using bands 7, 5, and 3 of the scanner, is presented in Figure 4. The image is a georeferenced mosaic of three flightlines, orthorectified with the DEM from ORNL and geocoded in UTM Zone 16S Projection, WGS 84 geoid. 


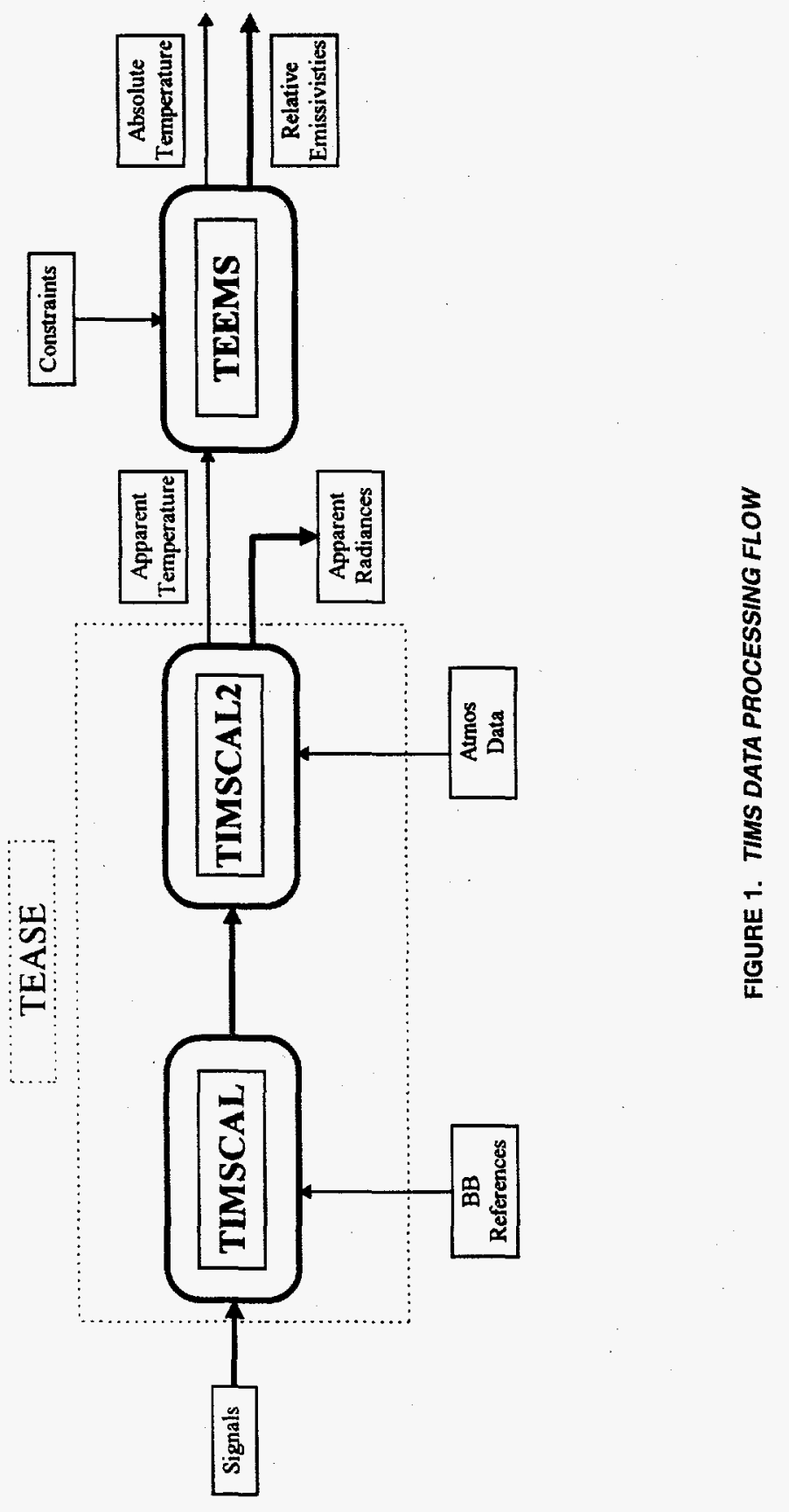




\section{TIMS Imagery}

\section{Gray-Level Temperature (Degrees Centigrade)}

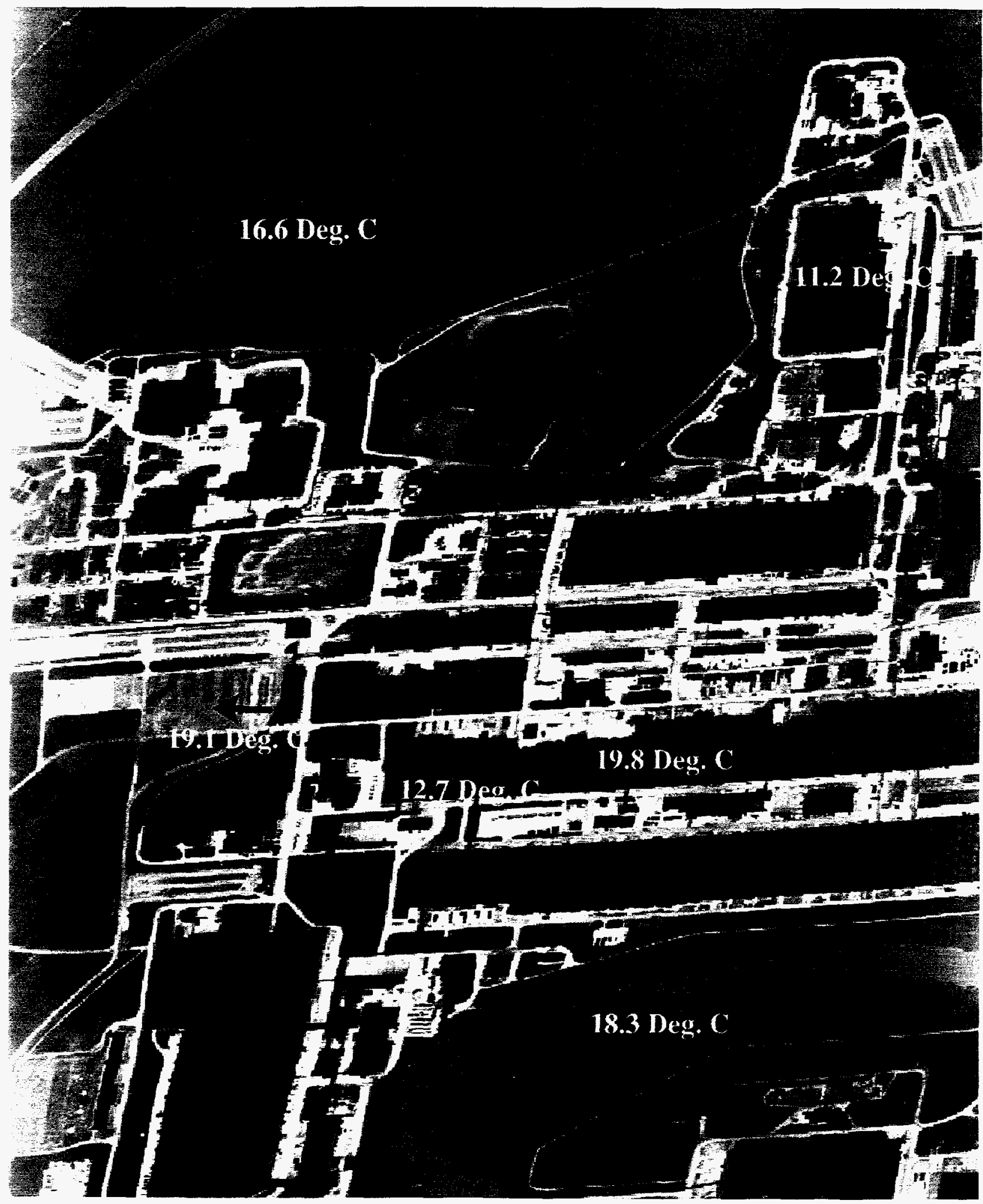




\section{TIMS Imagery}

\section{Emissivity Band 3}

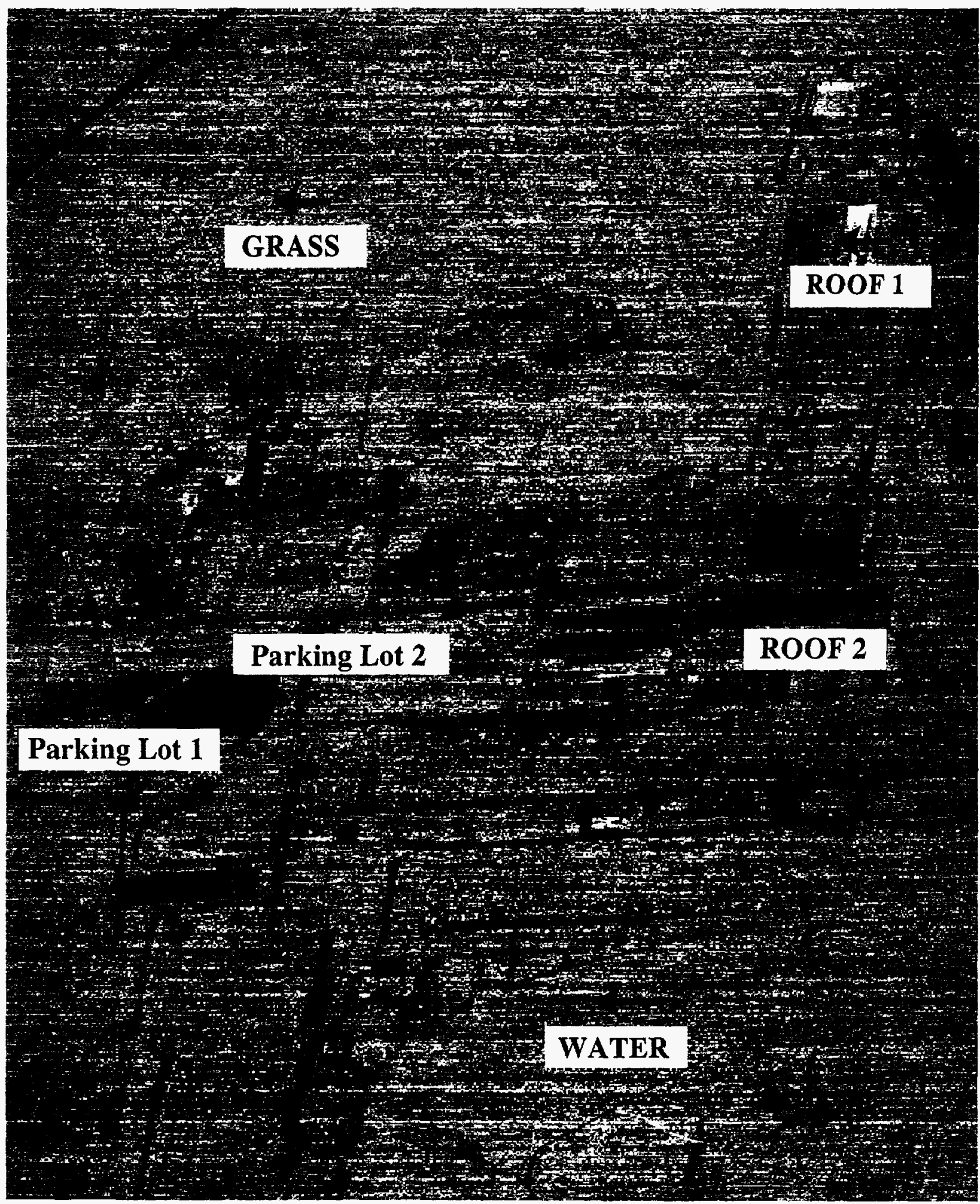

FIGURE 3. EXAMPLE OF ESTIMATED EMISSIVITY IMAGE FOR TIMS CHANNEL 3

Bechtel Iovada 


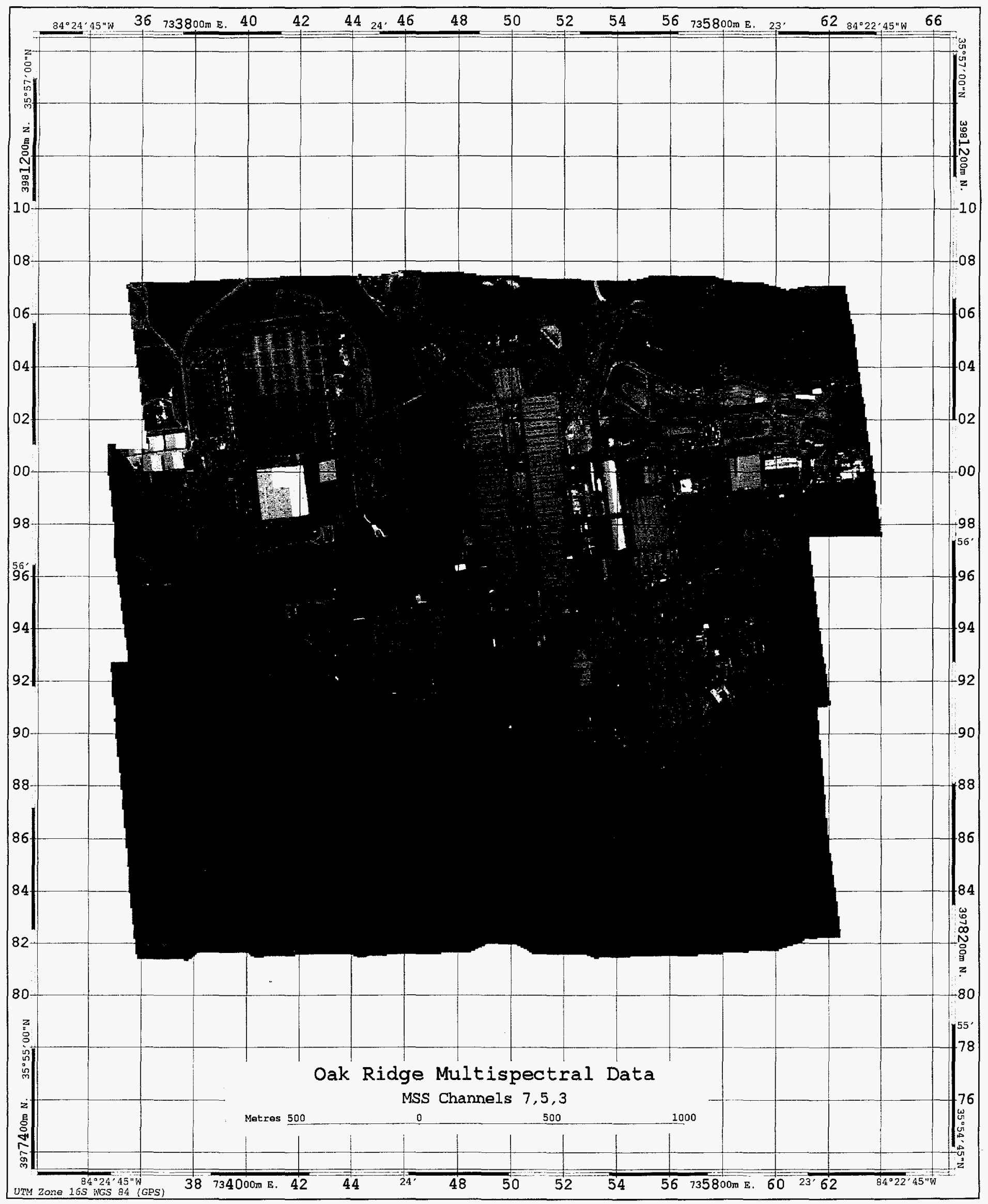

FIGURE 4. GEOCODED, ORTHORECTIFIED, AND MOSAICKED MULTISPECTRAL IMAGE OF K-25 (CHANNELS 7, 5, AND 3) 


\section{APPENDIX A \\ OVERLAY OF FLIGHTLINES}




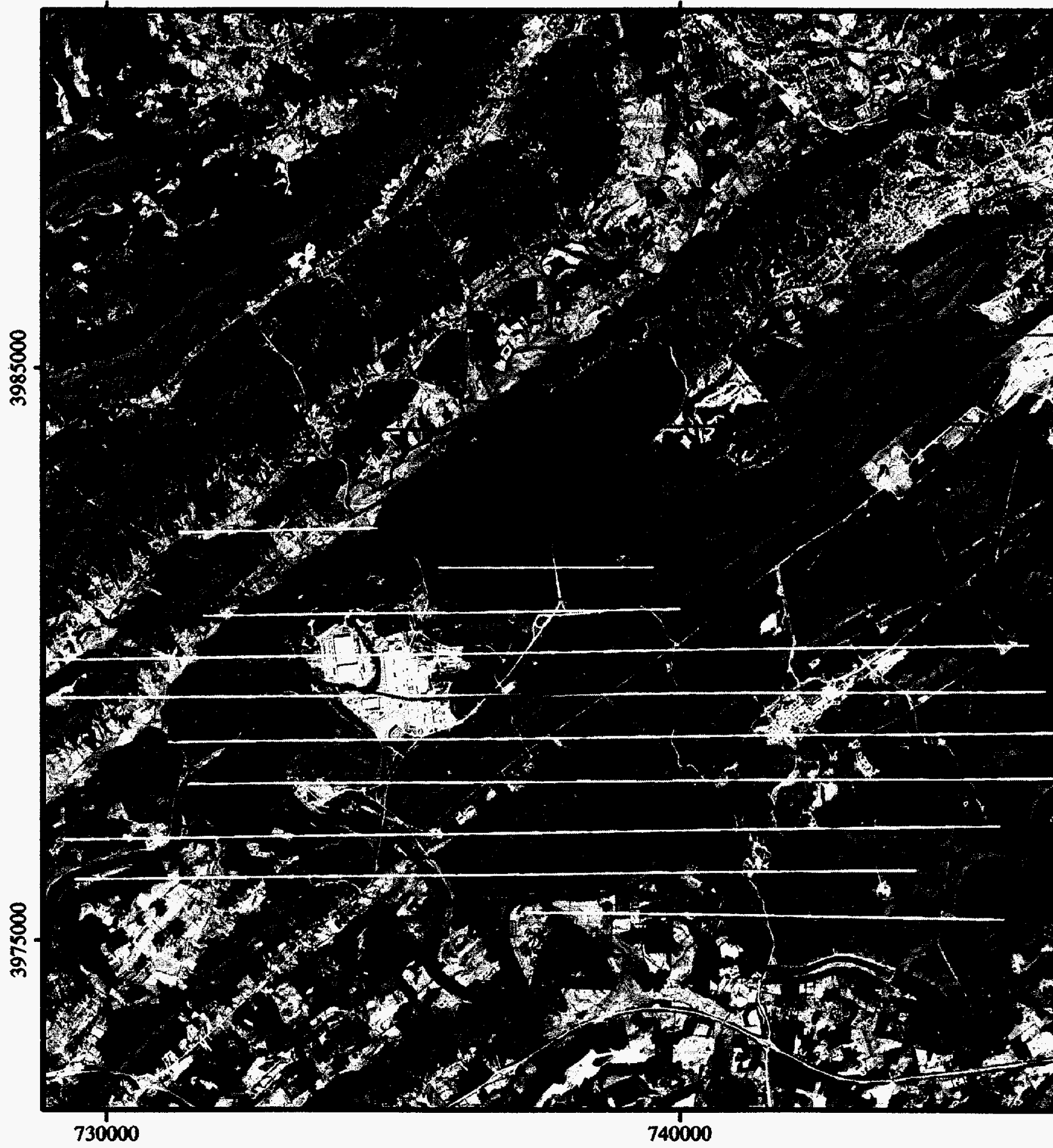




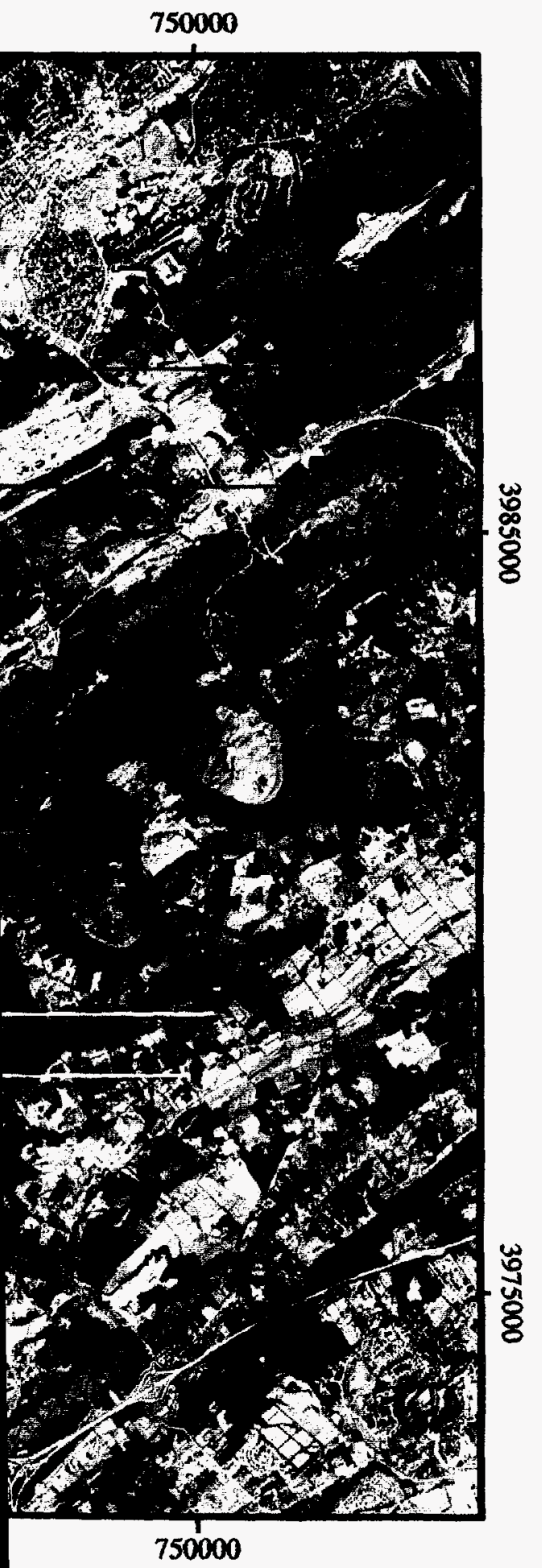

\title{
ORNL 2000' and 4000' Daytime MSS Flight Lines
}

\author{
5 June 1996
}

2000' AGL

$4000^{\prime}$ AGL

Scale 1:105000
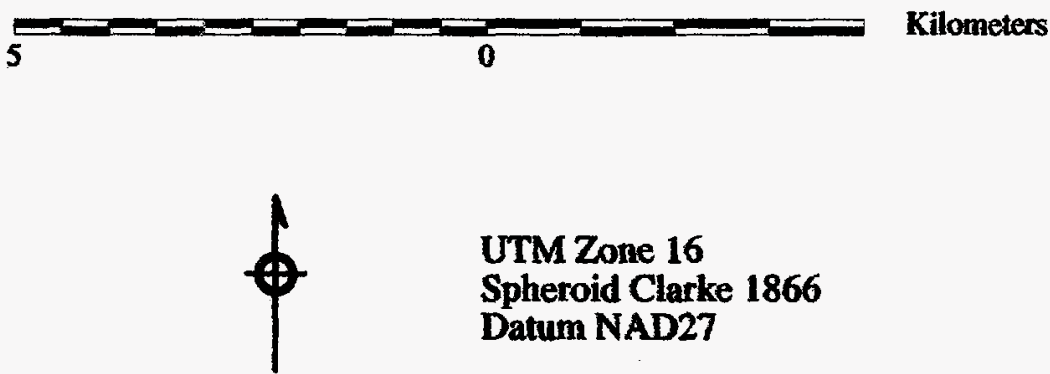

Flight-line data acquired by the USDOE Remote Sensing Laboratory operated by Bechtel Nevada. Flight lines overlaid on SPOT panchromatic image acquired 21 January 1992. 


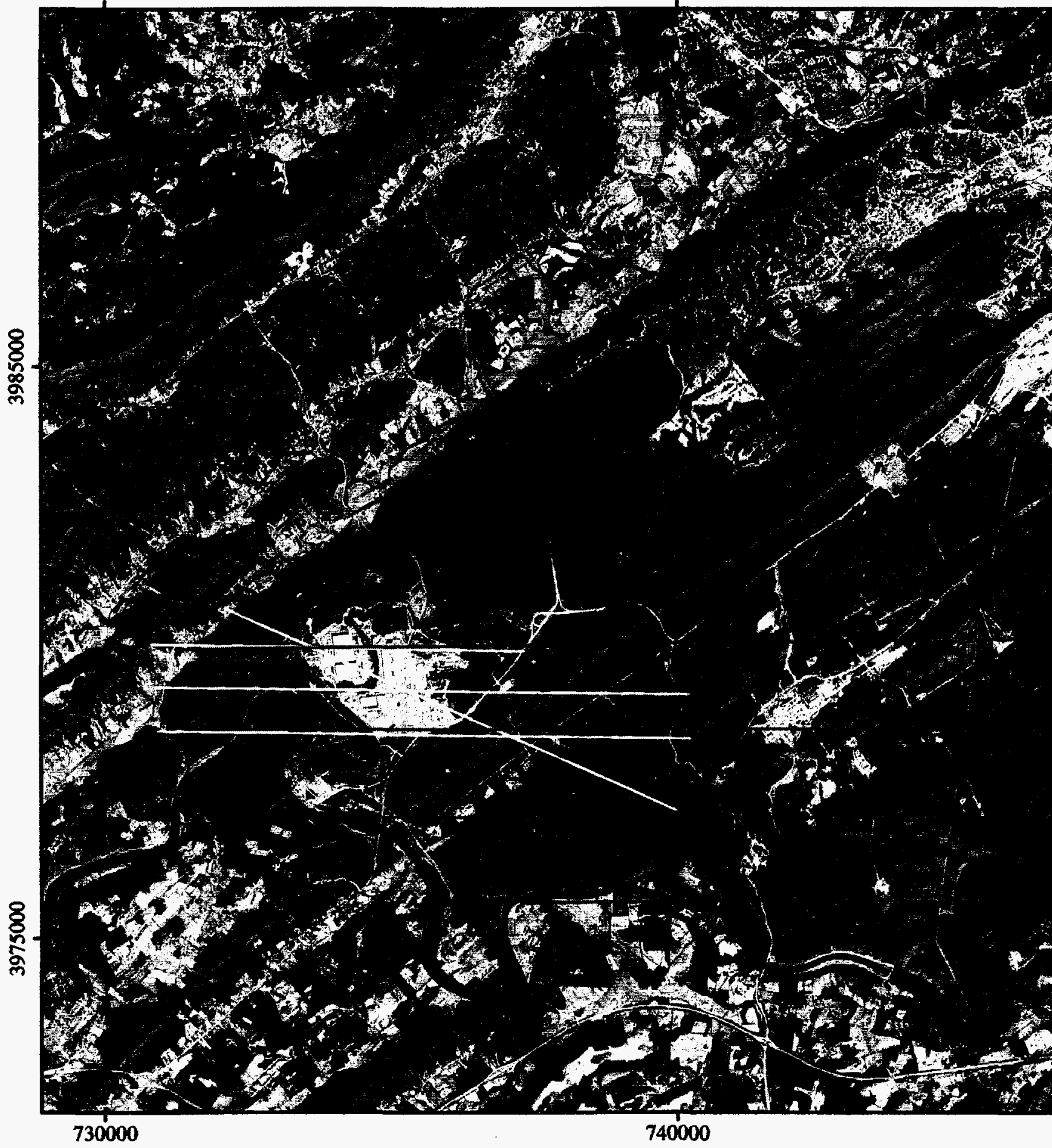




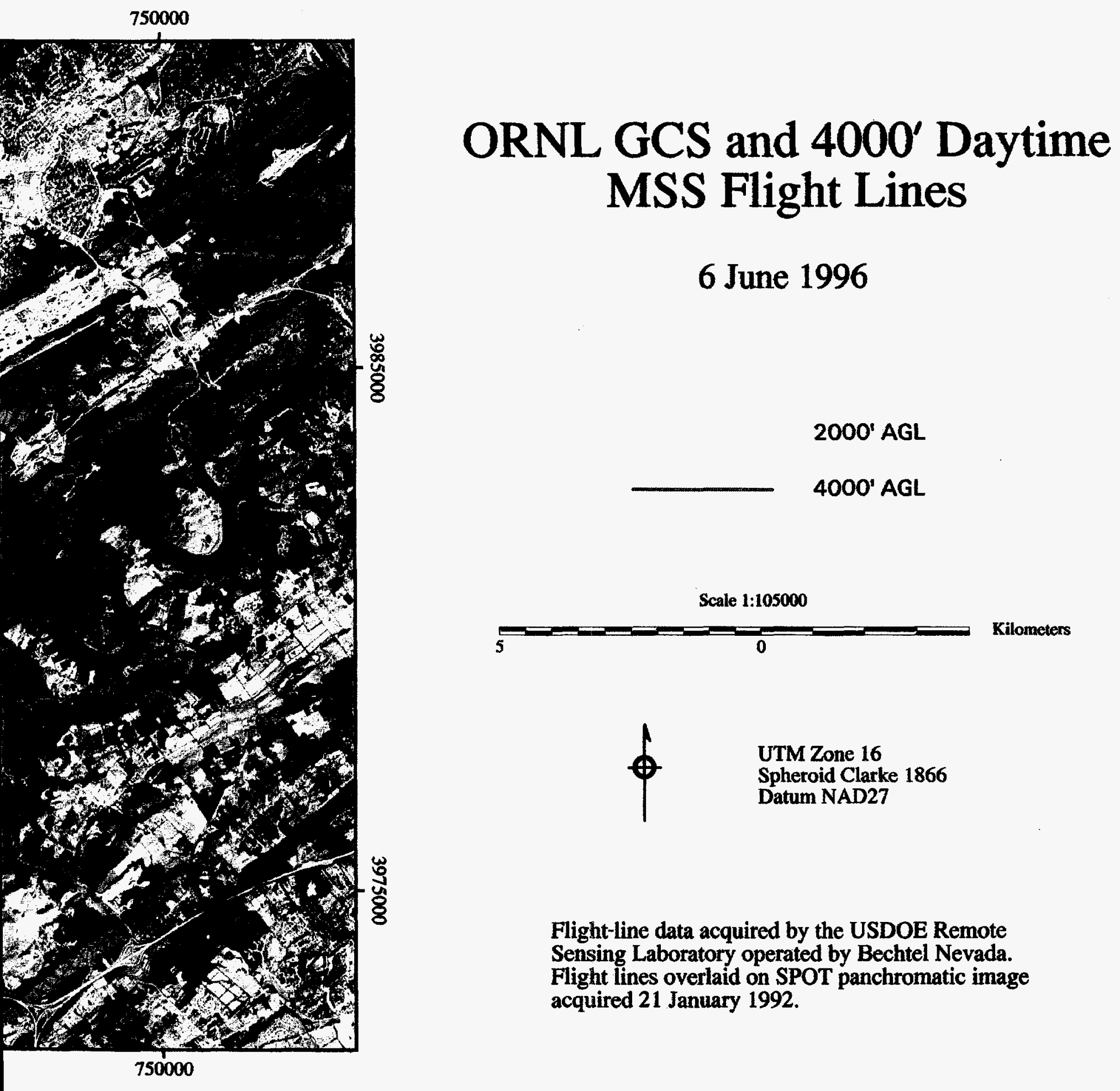




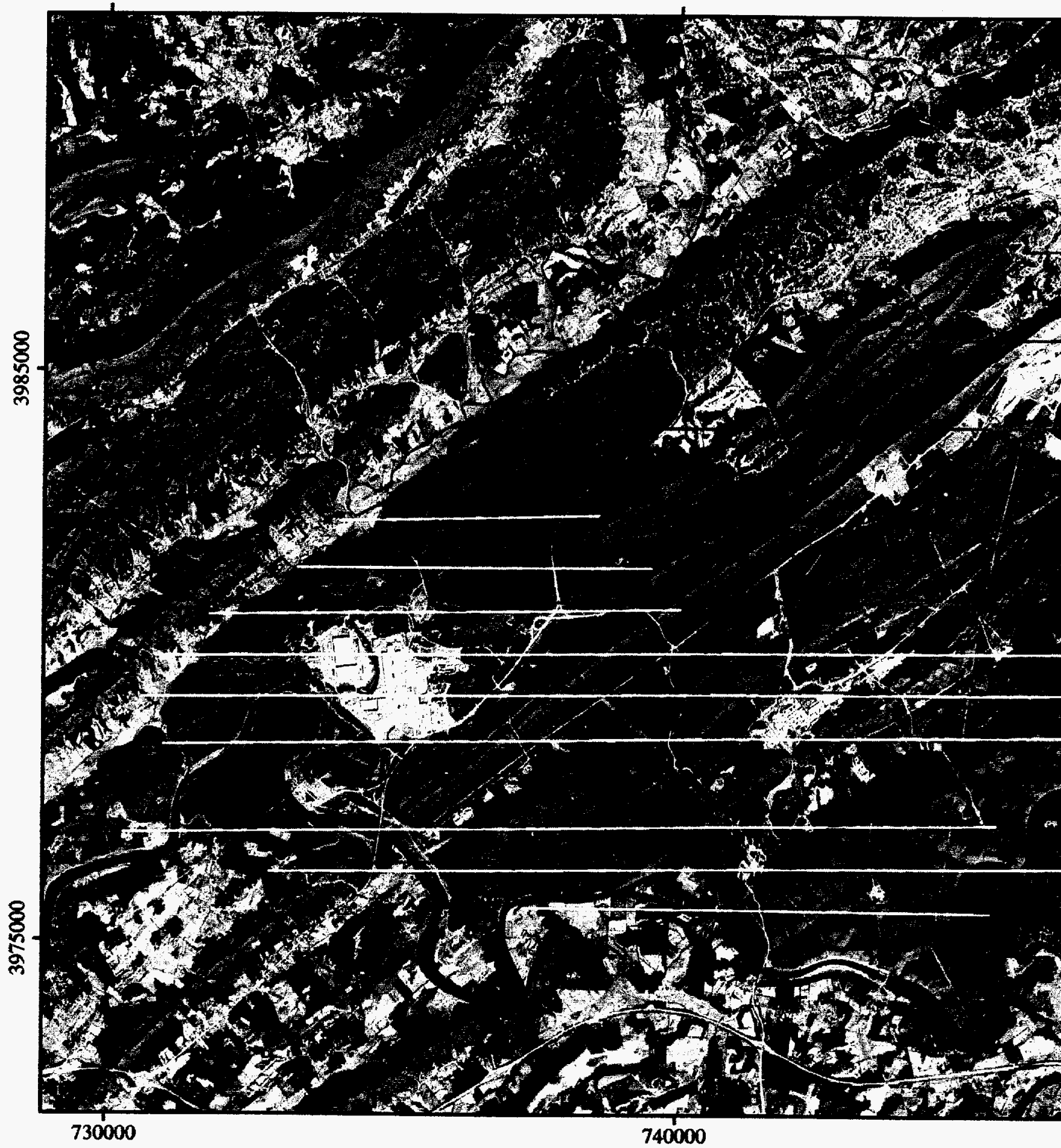




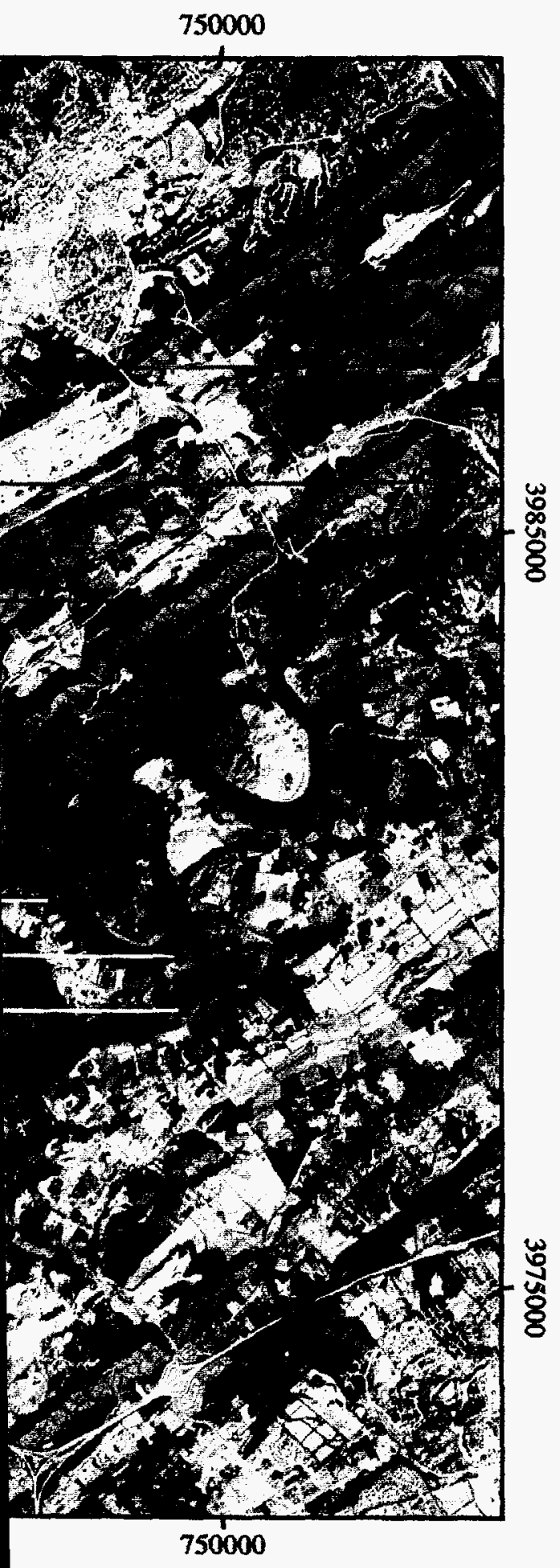

\title{
ORNL Predawn MSS Flight Lines
}

\author{
7 June 1996
}

2000' AGL

4000' AGL

Scale 1:105000

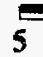

0

Kilometers

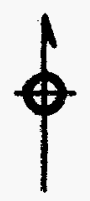

UTM Zone 16

Spheroid Clarke 1866

Datum NAD27

Flight-line data acquired by the USDOE Remote Sensing Laboratory operated by Bechtel Nevada. Flight lines overlaid on SPOT panchromatic image acquired 21 January 1992. 


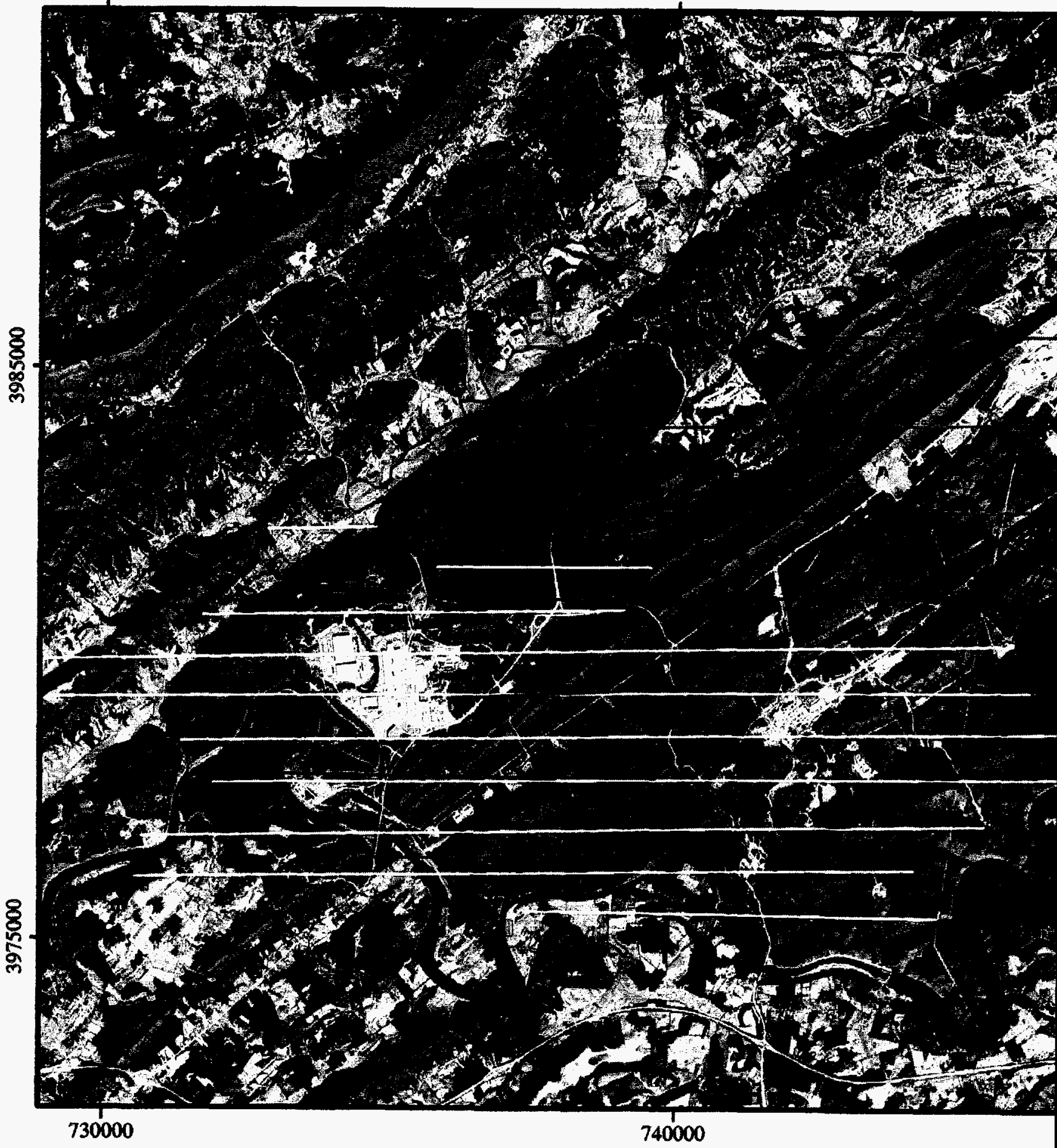




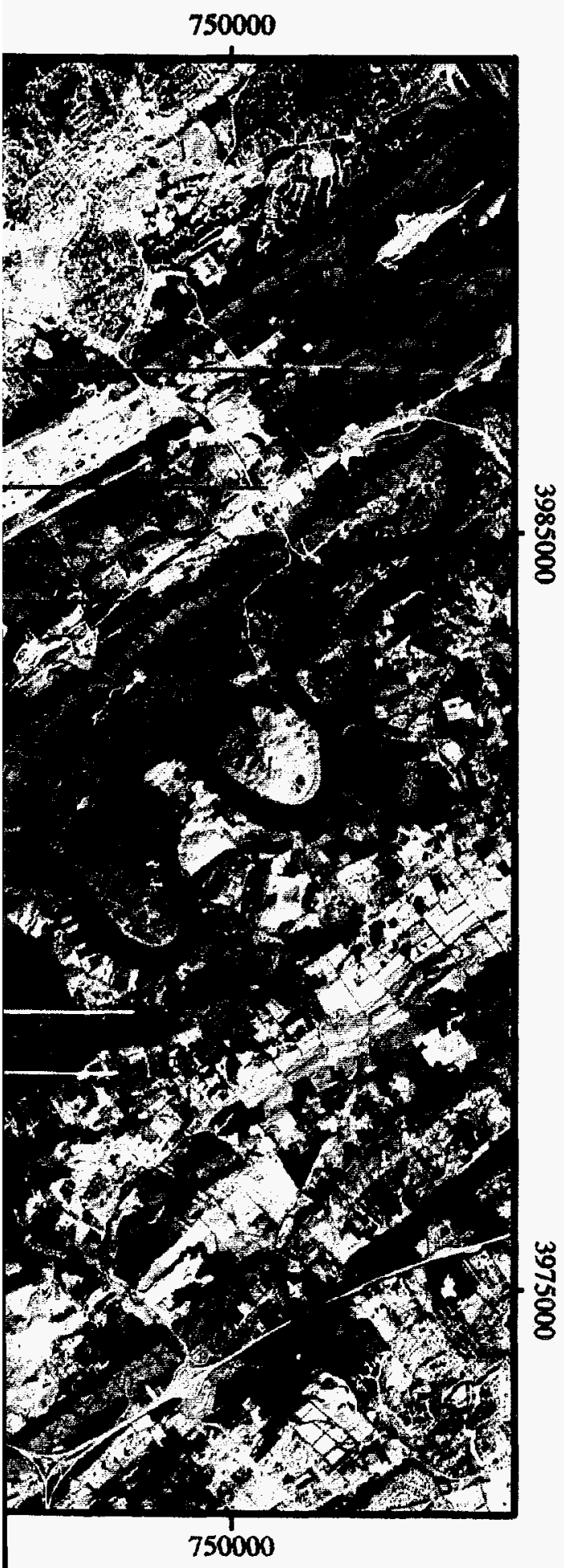

\title{
ORNL 2000' and 4000' Daytime TIMS Flight Lines
}

\author{
5 June 1996
}

$2000^{\prime}$ AGL

$4000^{\prime}$ AGL

Scale 1:105000

5

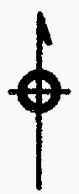

UTM Zone 16

Spheroid Clarke 1866

Datum NAD27

Flight-line data acquired by the USDOE Remote Sensing Laboratory operated by Bechtel Nevada. Flight lines overlaid on SPOT panchromatic image acquired 21 January 1992. 


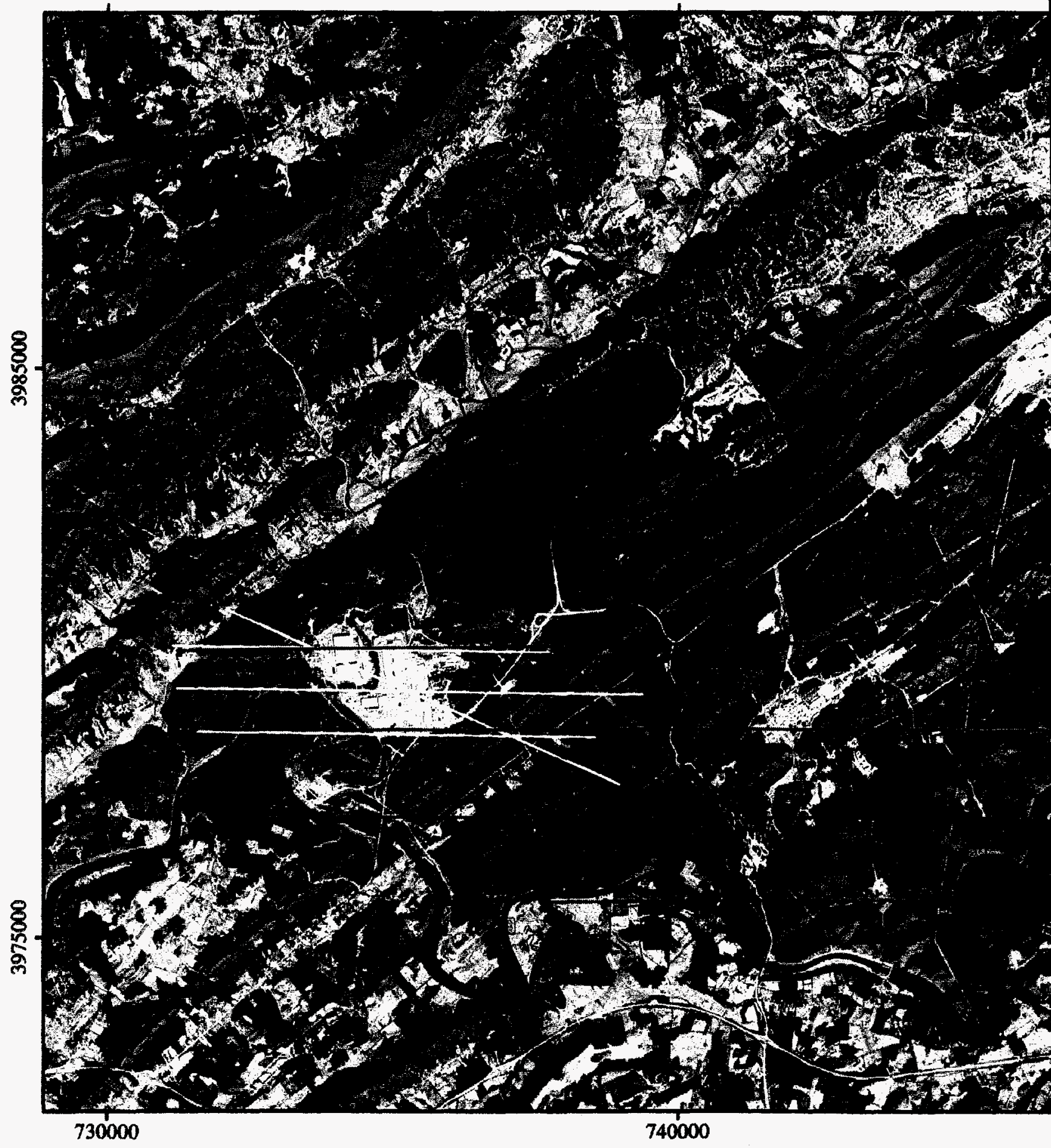




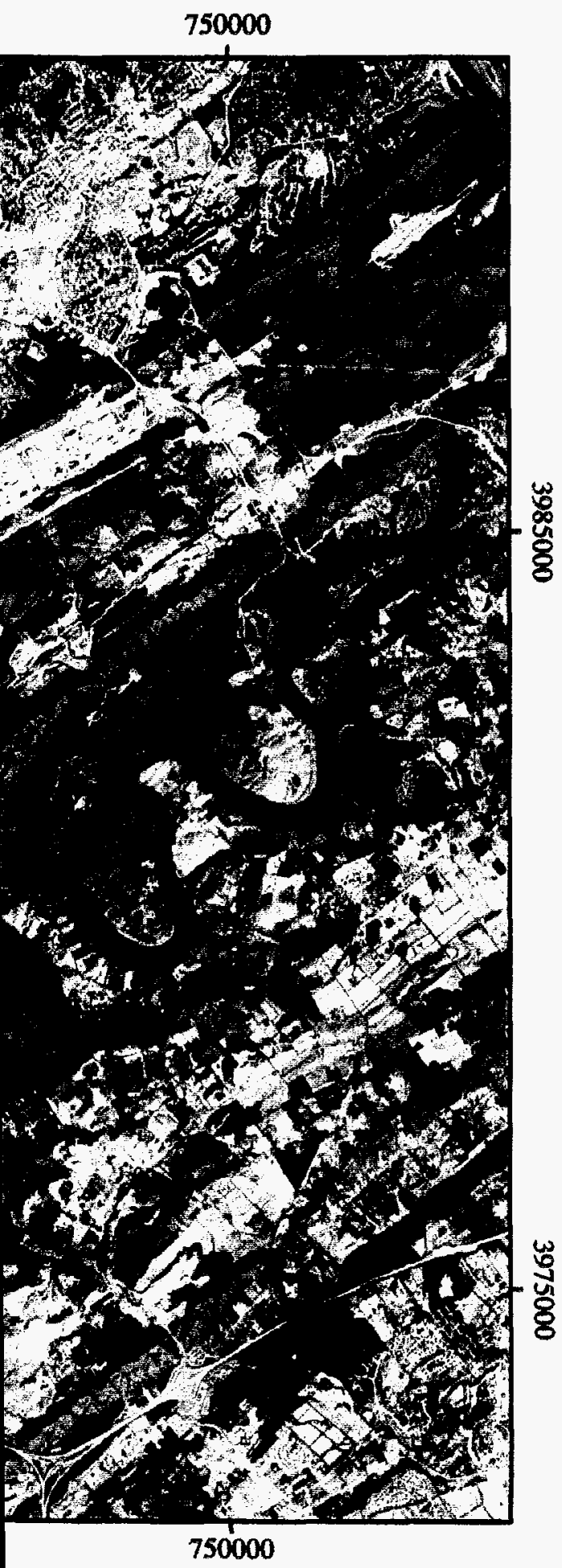

\title{
ORNL GCS and 4000' Daytime TIMS Flight Lines
}

\author{
6 June 1996
}

岁
용

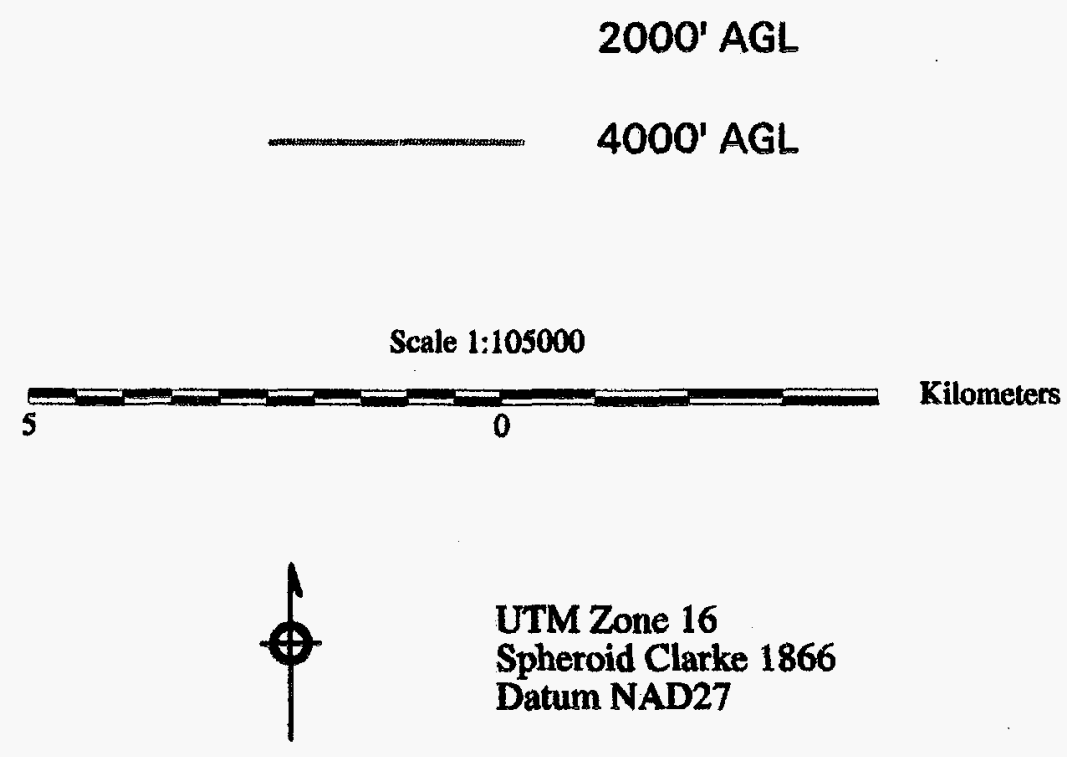

Flight-line data acquired by the USDOE Remote Sensing Laboratory operated by Bechtel Nevada. Flight lines overlaid on SPOT panchromatic image acquired 21 January 1992. 


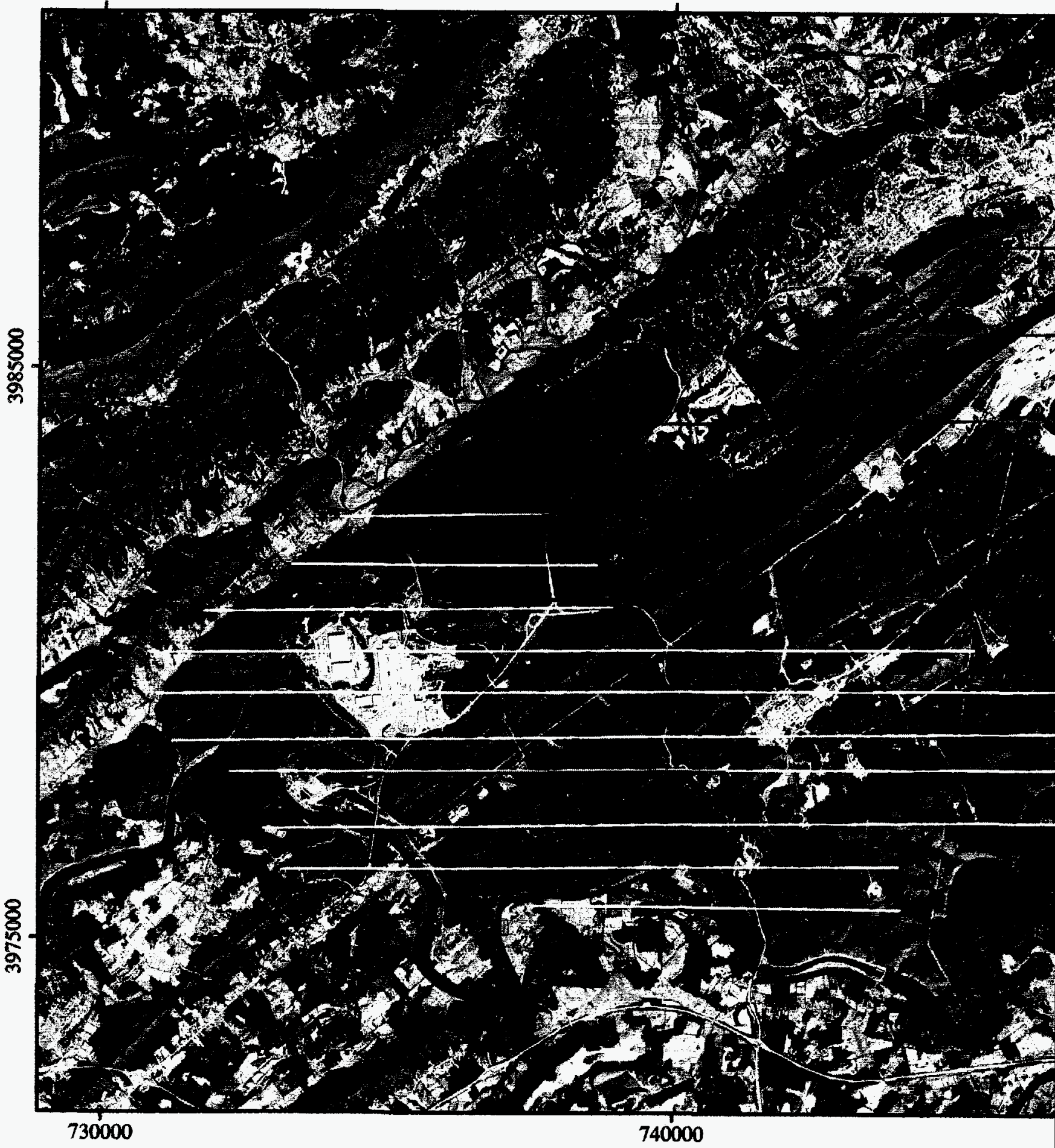




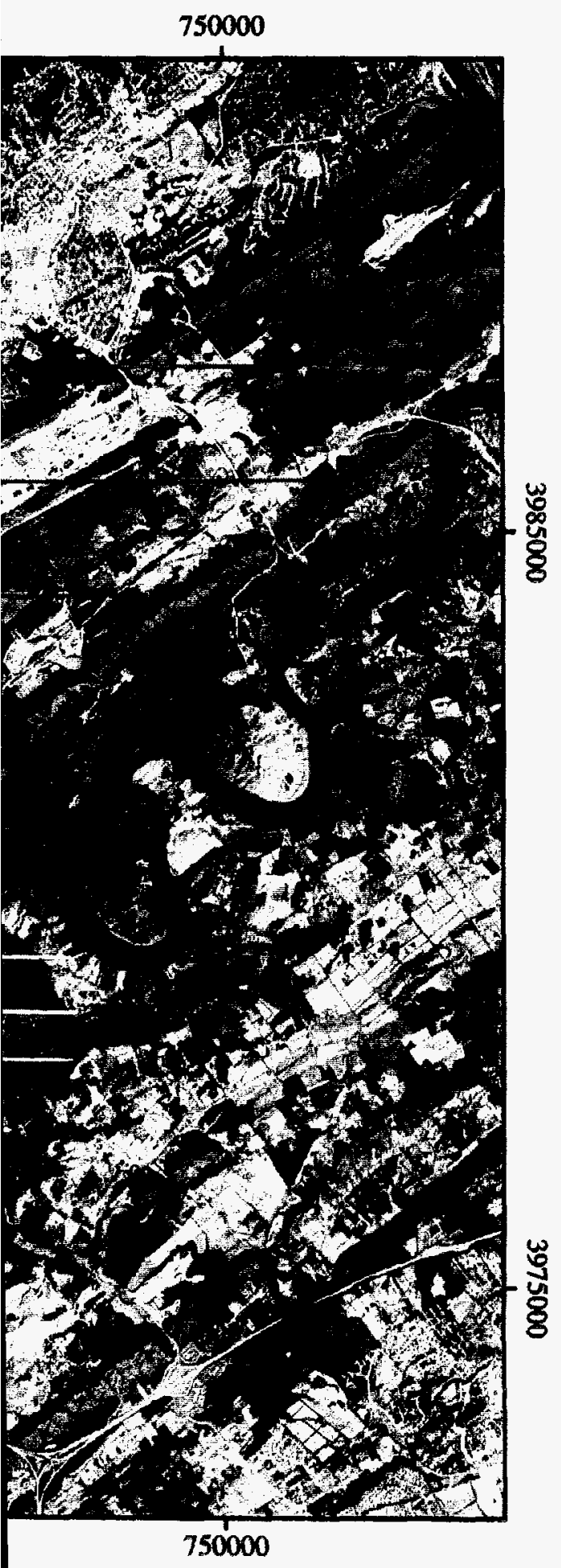

\title{
ORNL Predawn TIMS Flight Lines
}

\author{
7 June 1996
}

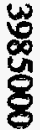

2000' AGL

4000' AGL

Scale 1:105000

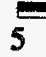

0

Kilometers

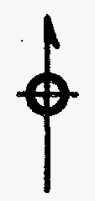

UTM Zone 16

Spheroid Clarke 1866

Datum NAD27

Flight-line data acquired by the USDOE Remote

Sensing Laboratory operated by Bechtel Nevada. Flight lines overlaid on SPOT panchromatic image acquired 21 January 1992. 


\section{APPENDIX B}

\section{PROCESSING OF TIMS DATA}

This appendix describes in more detail the generation of the absolute temperature and emissivity images from the TIMSCAL2 output image and the organization of the delivered CD-ROMs.

The process began by looking through the TIMSCAL2 source code to find the TIMS sensor characterization data. Table A-1 shows the latest characterization data created by JPL in May 1996 and used to calculate the center wavelengths for each of the six bands.

Table A-1. Data Derived from JPL Measurements

\begin{tabular}{c|c|c|c|c|c}
\hline Band & $\begin{array}{c}\text { Short } \\
\text { Wavelength }\end{array}$ & $\begin{array}{c}\text { Center } \\
\text { Wavelength }\end{array}$ & $\begin{array}{c}\text { Long } \\
\text { Wavelength }\end{array}$ & $\begin{array}{c}\text { Filter } \\
\text { Bandpass }\end{array}$ & $\begin{array}{c}\text { Normalized } \\
\text { Responsivity }\end{array}$ \\
\hline 1 & 8.131299 & $\mathbf{8 . 3 9 3 3 7 5}$ & 8.655450 & 0.524151 & 0.714717 \\
\hline 2 & 8.558444 & $\mathbf{8 . 7 9 4 0 1 4}$ & 9.029584 & 0.471140 & 0.781907 \\
\hline 3 & 8.876357 & $\mathbf{9 . 1 8 6 9 6 2}$ & 9.497567 & 0.621209 & 0.516609 \\
\hline 4 & 9.471120 & $\mathbf{9 . 8 6 8 0 7 8}$ & 10.265036 & 0.793915 & 0.875767 \\
\hline 5 & 10.207658 & $\mathbf{1 0 . 7 0 5 2 6 7}$ & 11.202877 & 0.995219 & 0.852721 \\
\hline 6 & 11.108795 & $\mathbf{1 1 . 6 2 6 2 0 0}$ & 12.143606 & 1.034811 & 0.673833 \\
\hline
\end{tabular}

Only the center wavelength data values are critical to the calculations producing the absolute temperature and emissivity image files.

The sensor data are recorded in band-interleave by line (BIL) format with each record being 750 bytes in length. Although there are only six channels of actual data per record, the raw data contains an additional seventh data channel for each record. This seventh channel contains no valid data and is ignored. The raw TIMS data are also written in fixed 32-kilobyte (32768-byte) records. This means that after every six lines of 7 -channel TIMS data there are 1268 bytes of padding to fill up the remainder of the 32768-byte block. Table A-2 describes the format of the raw TIMS data file.

Table A-2. Raw TIMS Data Block

\begin{tabular}{|ll|}
\hline Record 1 \\
\hline Channel 1 Data Record & (750 bytes) \\
\hline Channel 2 Data Record & (750 bytes) \\
\hline Channel 3 Data Record & (750 bytes) \\
\hline Channel 4 Data Record & (750 bytes) \\
\hline
\end{tabular}


Table A-2. Raw TIMS Data Block (continued)

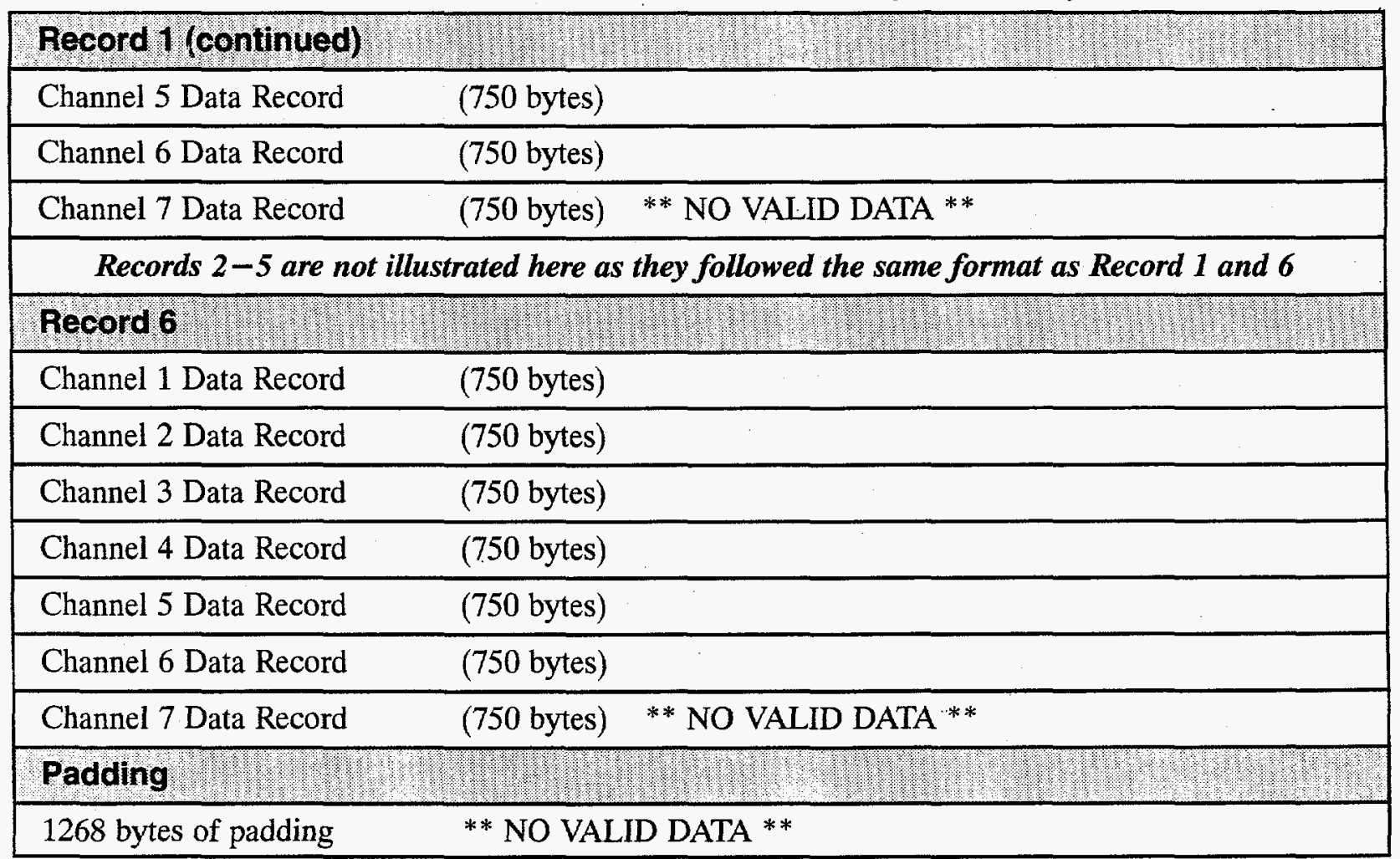

The JPL TEASE software (the TIMSCAL2 program in particular) requires the data to be inputted in a raw, unprocessed form, including the headers and other padding.

Before applying the RSL TEEMS algorithm for deriving temperature and emissivity, RSL had to develop a program to provide data in the appropriate form and with the necessary auxiliary data-the "TIMSVALS" program. This program scans the raw TIMS data and tracks the minimum and maximum blackbody values together with their corresponding digital values for each of the six channels. This information is displayed for the user with calculated bracketing temperatures to be used later with the "TEEMS" program.

The second program developed was the "TEEMS" program. This is the main data processing program. Its function is to produce an "absolute" temperature image file and a six-banded emissivity image file from an "apparent" temperature image file produced by TIMSCAL2. In order to accomplish this, TEEMS uses the apparent temperature data from two of the six bands obtained from TIMSCAL2 along with the bracketing temperatures determined by the TIMSVALS program. The apparent temperatures are used in pairs, one value taken from each of the selected bands. If either of these temperatures falls outside the bracketed temperature range, the corresponding value in the output images will be flagged because they are either clipped or saturated, depending on which side of the bracket they fall. Clipped values are set at $\mathbf{- 9 9}$, and saturated values are set at 99 . If both apparent 
temperatures fall within the bracketed temperature range, then the values are used in the calculation of absolute temperature.

To find the absolute temperature for a given pixel, TEEMS calculates the roots of the derived equation for temperature using the Newton-Raphson technique. Because the equation is nonlinear having two roots, the program must select the appropriate root to use as the true temperature. The technique to perform this selection is to first find the high-value root. If this root falls within the bracketed temperature range, then this root is the one selected. If the high-value root falls outside of the bracketed temperature range, then the low-value root is calculated. Of the high-value root and the low-value root, the root that is closest in absolute value to the two input temperatures is selected. Once the appropriate root has been selected, the program proceeds to calculate the six emissivity values based from the Planck or Wein equations. This process is repeated for each temperature pair in the input image. The final output of this program includes an absolute temperature image and a six-banded emissivity image. Each data record in the output images contains 638 data values (pixels) and each pixel is stored as a 4-byte (32-bit) floating point number.

Due to physical constraints on the aircraft, the TIMS data scanner was installed backwards. This meant that the data would be acquired in a mirrored orientation from the direction of the flight. The correct orientation of the data was obtained by simply flipping the data horizontally. The TIMSFLIP program was developed to do this.

Once all of the data were processed, they were organized into five subdirectories where each subdirectory contained the data for one CD-ROM. Within each of the five subdirectories, the data were further organized into folders that were titled to reflect the acquisition date. Figure B-1 is a breakdown of the organization for the final processed TIMS data. 


\section{DISC1}

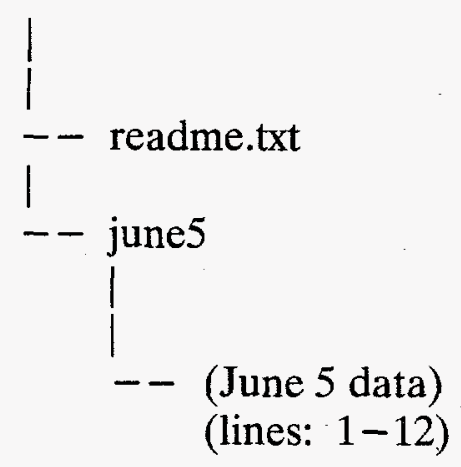

\section{DISC3}

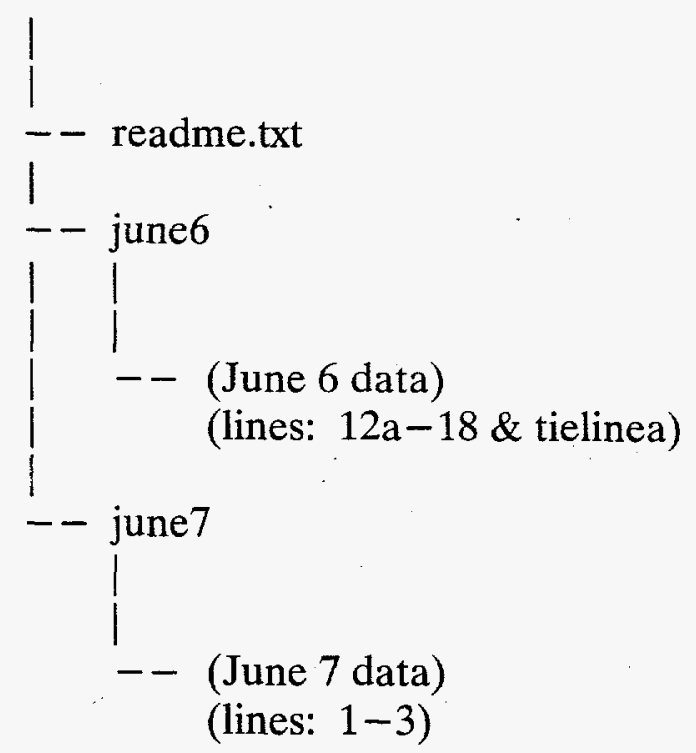

\section{DISC2}

1

- readme.txt

I

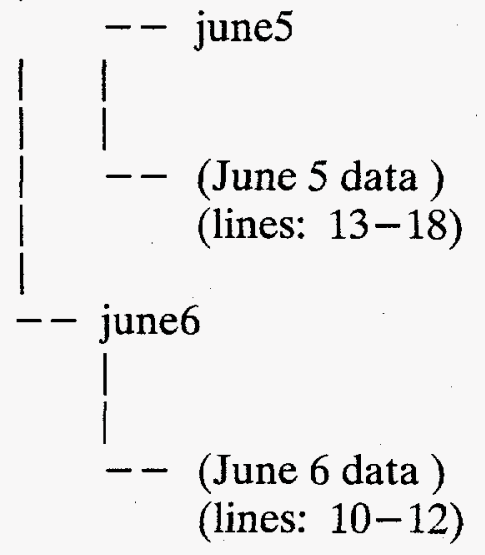

\section{DISC4}

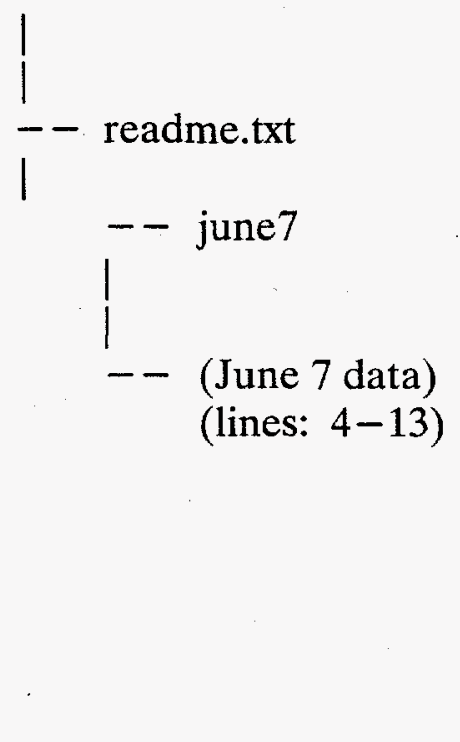

\section{DISC5}

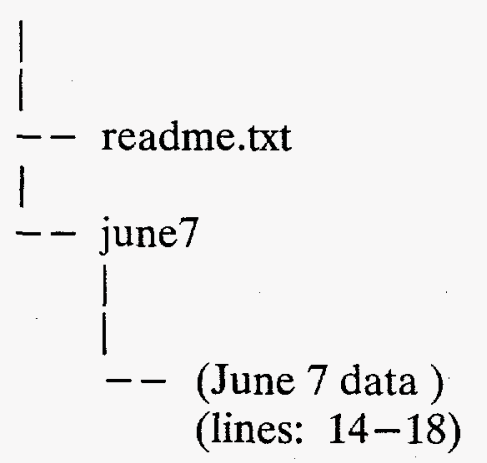

FIGURE B - 1. DIRECTORY AND FILE STRUCTURE FOR PROCESSED TIMS DATA 


\section{REFERENCES}

1. Palmer, J.M. and M.G. Tomasko. Optics Letters. 5:208; 1980. 


\section{DOE/DP}

R. Ghetti

(1)

DOE/NSIC

R. S. Scott

(1)

K. D. Lachman

Public Reading Room

TIO

TIRC

(1)

\section{ORNL}

A. King

(2)

\section{BN}

I.W. Ginsberg LVAO

(1)

R.E. Kelley

LVAO

K.R. Lamison LVAO

(1)

J.T. Mitchell

LVAO

L.G. Sasso

LVAO

\section{LIBRARY}

RSL

(3)

OSTI

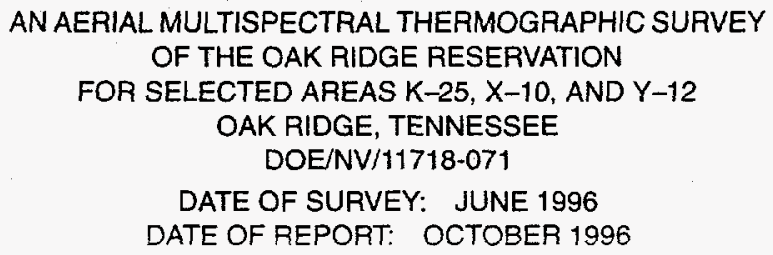

